\title{
INTERAÇÃO DO MYCOPLASMA BOVIGENITALIUM COM CÉLULAS DO CUMULUS IN VITRO APÓS O PERÍODO DE MATURAÇÃO OOCITÁRIA BOVINA
}

\author{
A.C. Goes, M.F. Alves, D.L. Pavão, M.M. Piccolomini, M.L. Batista, E.G. Palazzi, M. D’Angelo \\ Instituto Biológico, Centro de Pesquisa e Desenvolvimento de Sanidade Animal, Av. Cons. Rodrigues Alves, \\ 1252, CEP 04014-002, São Paulo, SP, Brasil. E-mail: dangelo@biologico.sp.gov.br
}

\section{RESUMO}

O Mycoplasma é considerado cosmopolita, podendo ser disseminado através do comércio internacional de animais, sêmen industrializado e de produtos de transferência de embriões. A expansão de células do cumulus é utilizada como parâmetro de avaliação de oócitos bovinos cultivados in vitro e suas alterações morfológicas são representativas. O objetivo deste trabalho foi avaliar a interação do Mycoplasma bovigenitalium, exposto experimentalmente à cultura primária de célula do cumulus, após o período de maturação. Complexos oócitos cumulus (COCs) obtidos através de punção folicular de ovários bovinos, provenientes de abatedouro, foram divididos em dois grupos para serem maturados durante 24h em meio de maturação (TCM199 + hormônios) em estufa a $38^{\circ} \mathrm{C}, 5 \%$ de $\mathrm{CO}_{2}, 95 \%$ de umidade. Posteriormente, os oócitos foram retirados das placas, permanecendo somente com as células do cumulus aderidas. Com o monoestrato celular formado, um grupo foi infectado com $30 \mathrm{~mL}$ de $M$. bovigenitalium, replicado em meio Hayflick modificado a $37^{\circ} \mathrm{C}$ em estufa de microaerofilia, enquanto o outro foi mantido como controle. Os resultados mostraram que, com $24 \mathrm{~h}$ de exposição ao patógeno, as culturas apresentaram um pequeno número de células arredondadas e granulosas, quando comparadas as dos controles. Esse efeito persistiu até o sétimo dia, onde se iniciou um processo de descolamento das células. Pode-se concluir que uma contaminação por micoplasma pode ser imperceptível às manipulações da FIV, pois células infectadas por esse grupo de bactérias não apresentam turvações no meio de cultura e, quando não lisam a célula hospedeira, tornam mais suscetível ao ambiente e outros agentes infecciosos.

PALAVRAS-CHAVE: Mycoplasma bovigenitalium, complexos oócitos cumulus (COCs), culturas, fecundação in vitro de embriões (FIV).

\begin{abstract}
INTERACTION OF MYCOPLASMA BOVIGENITALIUM WITH PRIMARY-CULTURE CUMULUS CELLS AFTER IN VITRO MATURATION PERIOD. The Mycoplasma is considered cosmopolitan and can be disseminated through international trade of animals, industrialized semen and embryo transfer products. The expansion of cumulus cells is used as a parameter for evaluating cattle oocytes cultivated in vitro, and their morphological changes are representative. The aim of the present study was to evaluate the interaction of Mycoplasma bovigenitalium with primary-culture cumulus cells, after the in vitro maturation period. Cumulus complex oocytes (COCs) obtained through follicular puncture of ovaries from a cattle slaughterhouse were divided into two groups to be matured for 24 hours in the maturation medium (TCM $199+$ hormones) in a climate controlled chamber at $38^{\circ} \mathrm{C}, 5 \% \mathrm{CO}_{2}$, and $95 \%$ humidity. Subsequently, the oocytes were removed from the plates, which remained with only the cumulus cells attached. With the monostratum cell formed, one group was infected with $30 \mu \mathrm{L}\left(5 \times 10^{6}\right.$ cells $\left./ \mathrm{mL}\right)$ M. bovigenitalium, replicated in modified Hayflick medium at $37^{\circ} \mathrm{C}$ in a mycroaerofilic chamber, while the other was kept as a control. The results showed that with 24 hours of exposure to the pathogen, the cultures showed a small number of rounded and grainy cells, when compared to the controls. This effect persisted until the 7th day, when a process of cell detachment began. It can be concluded that a mycoplasma contamination may be imperceptible to the manipulations of FIV, because cells infected by this group of bacteria present no cloudiness in the culture field, and when they do not lyse the host cell, they make it more susceptible to environment and other infectious agents.
\end{abstract}

KEY WORDS: Mycoplasma bovigenitalium, cumulus complex oocytes (COCs), primary culture, in vitro fertilization (IVF). 


\section{INTRODUÇÃO}

A cada nova biotecnologia que surge na área de reprodução animal, observa-se um crescente interesse no controle da transmissão de doenças infecciosas. Do ponto de vista epidemiológico, os novos ambientes favoráveis ao crescimento de microorganismos e a manipulação excessiva do material, possibilitam a contaminação e disseminação de patógenos (STRINGFELLow et al., 2004).

A maioria dos sistemas usados para produção de embriões por fertilização in vitro (FIV) requer meios complexos com algum tipo de soro ou células de suporte, que provêm um ambiente favorável para o desenvolvimento embrionário (D'ANGELO et al., 2003; GONÇAlves et al., 1997; KRISHER; BAVISTER, 1998; SPARKS et al., 1994), mas podendo permitir facilmente a introdução e manutenção de micro-organismos no sistema (D'ANGELO et al., 2002).

Doenças infecciosas como a brucelose, leptospirose, campilobacteriose, rinotraqueíte infecciosa bovina, diarreia viral bovina e tricomoníase afetam diretamente a reprodução animal (KirKBride, 1987; EAglesome et al., 1992). Porém, as micoplasmoses (Mollicutes), pouco divulgadas, deveriam ser investigadas, pois resultam em quadro sintomatológico semelhante aquelas citadas acima, além de constar na lista de doenças de notificação obrigatória da Organização Internacional de Epizootias (OIE), como doenças suscetíveis de serem transmitidas pela inseminação artificial (ThibIER; Guerin, 2000; DoIG, 1981; Nascimento et al., 2005).

OMycoplasma éconsiderado cosmopolita podendo ser disseminado através do comércio internacional de animais, sêmen industrializado e de produtos de transferência de embriões (TE) (BRITTON et al., 1998; MiLLER et al., 1994).

Entreas espécies isoladas de bovinos, o Mycoplasma bovigenitalium é considerado um dos patógenos de maior importância para o trato genital (AHMED et al., 1998). Sua infecçãoé caracterizada por vulvovaginite granular, com descarga vaginal mucopurulenta, podendo ou não apresentar infertilidade. Mastite e abortos também são relatados (EAGLESOME et al.,1992; AHMED et al., 1998; DoIG, 1981).

Sistemas de co-cultura com células do cumulus e células epiteliais do oviduto bovino têm sido utilizados para o desenvolvimento e maturação de oócitos para posterior utilização em FIV de bovinos e obtenção de um maior número de embriões, respectivamente (HERNANDEZ-LEDEZMA et al., 1993; MiNAMI, 1996; SPARKS et al., 1992). Embora não sejam submetidas a um controle de qualidade semelhante ao das culturas permanentes, são de fácil obtenção e manipulação, permitindo uma reprodutibilidade do experimento (D'ANGELO et al., 2002).
Sabe-se que o complexo cumulus-oophorus compreende o oócito propriamente dito e células do cumulus, que exercem importante papel na regulação da maturação do oócito e, a retirada dessas células reduz significativamente o desenvolvimento embrionário subsequente. A expansão de células do cumulus é utilizada como parâmetro de avaliação de oócitos bovinos cultivados in vitro, demonstrando que suas alterações morfológicas passam a ser representativas (D'ANGELO et al., 2002).

Oobjetivo desse trabalho foi avaliar a interação do M. bovigenitalium, com células de culturas primárias do cumulus, após o período de maturação.

\section{MATERIAL E MÉTODOS}

\section{Bactéria}

O M. bovigenitalium foi isolado e cedido gentilmente pelo Laboratório de Doenças Bacterianas da Reprodução, e replicado em meio Hayflick modificado a $37^{\circ} \mathrm{C}$ em estufa de microaerofilia. Foram utilizados $30 \mu \mathrm{L}$ da bactéria, na concentração de $10^{3} \mathrm{UAC} / \mathrm{mL}$ (Unidades de alteração de cor por $\mathrm{mL}$ ).

\section{Obtenção de oócitos}

Os oócitos foram obtidos de ovários de vacas e novilhas no Abatedouro Mantiqueira, na Cidade de São José dos Campos, no Estado de São Paulo. Após a morte do animal, em aproximadamente 15 minutos, no momento da evisceração, os ovários foram colhidos, acondicionados e mantidos em solução fisiológica com $1 \%$ de penicilina e estreptomicina, a $37^{\circ} \mathrm{C}$ e transportados ao laboratório, não excedendo o período de 4 horas entre a sua obtenção e as aspirações foliculares (D'ANGELO, 1998).

Para a punção folicular, foram utilizadas seringas de $10 \mathrm{~mL}$ e agulha calibre 18G, ambas descartáveis. Após a punção, o conteúdo da seringa foi transferido para tubos tipo Falcon ${ }^{\circledR}$, devidamente tampados e levados à estufa a $37^{\circ} \mathrm{C}$ por 20 minutos para decantação dos oócitos. Este pellet foi coletado com pipetas do tipo Pasteur ${ }^{\circledR}$ e depositado em placas de Petri para devida seleção dos complexos cumulus-oócitos (COCs), com auxílio de solução de manutenção $\left(\mathrm{Cutilab}^{\mathrm{a}}\right)$, à temperatura de $37^{\circ} \mathrm{C}\left(\mathrm{D}^{\prime}\right.$ ANGelo, 1998).

\section{Maturação dos oócitos}

Uma vez selecionados, eles foram transferidos para gotas de meio de maturação (MIV), constituído de TCM199 (meio de cultivo de tecido 199), LH (hormônio luteinizante), FSH (hormônio folículo estimulante) e estreptomicina/penicilina, com 50 
mL cada, colocadas em placas de Petri descartáveis e imersas em óleo mineral filtrado. Dois grupos foram maturados em placas diferentes, durante 24 horas em MIV, em estufa a $38^{\circ} \mathrm{C}, 5 \%$ de $\mathrm{CO}_{2}, 95 \%$ umidade.

\section{Exposição dos COCs ao patógeno}

Após o período de maturação, os oócitos foram retirados das placas, que permaneceram somente com as células do cumulus aderidas. Já com o monoestrato celular formado, um grupo foi infectado com $30 \mathrm{~mL}$ de $M$. bovigenitalium $\left(10^{3} \mathrm{UAC} / \mathrm{mL}\right)$, e o outro foi mantido como controle.

Avaliação de alterações morfológicas nas células do expostas ao patógeno
A avaliação de alterações provocadas pelo $M$. bovigenitalium foi analisada através de microscopia óptica a fresco.

\section{RESULTADOS}

Os resultados mostraram que, com 24 horas de exposição ao patógeno, as culturas apresentaram um pequeno número de células arredondadas e granulosas, quando comparadas as dos controles (Fig. 1). Esse efeito persistiu até o sétimo dia, onde se iniciou um processo de descolamento das células (Fig. 2). Nas culturas controle, o descolamento ocorreu a partir do $13^{\circ}$ dia, período em que as células primárias iniciam a fase de senescência.

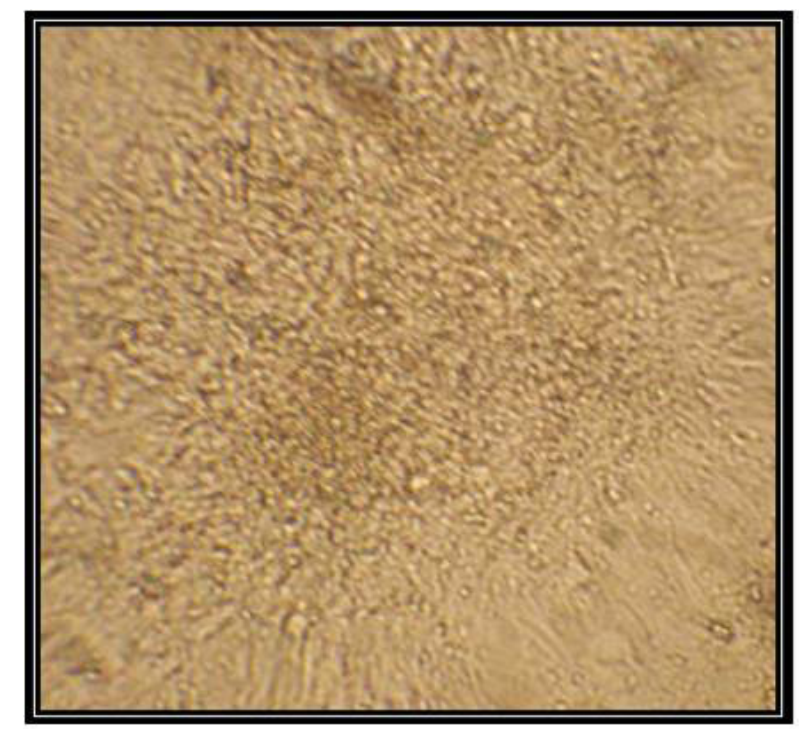

Fig. 1 - Grupo Controle de culturas primárias de células do cumulus após sete dias. (x200).

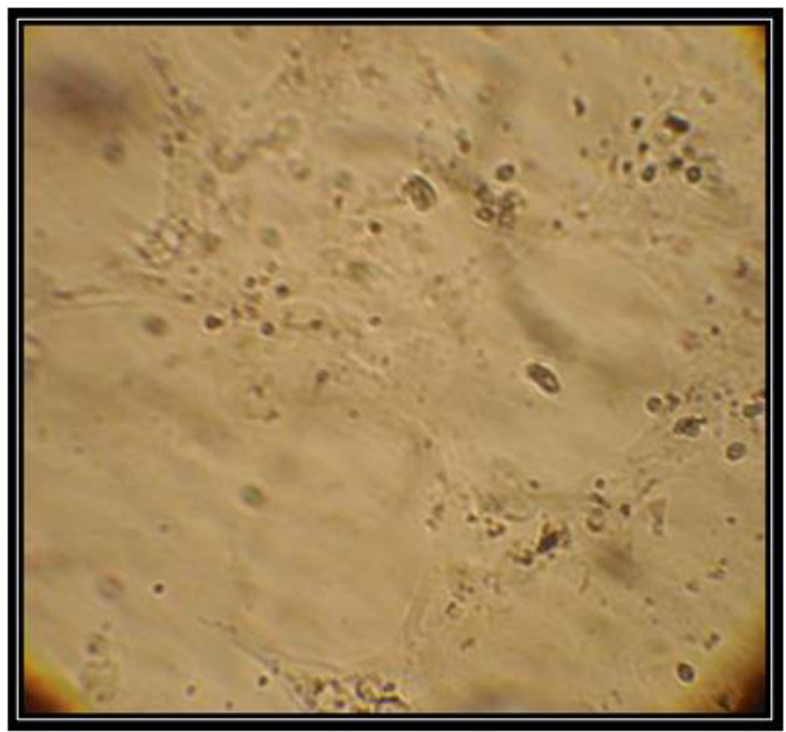

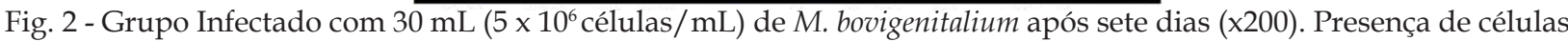
arredondadas e granulosas que persistem até o sétimo dia, onde se iniciou um processo de descolamento das células. 


\section{DISCUSSÃO}

A obtenção de um sistema de co-cultivo celular pode auxiliar, em muito, a aplicação de técnicas de micromanipulação (SPARKs et al., 1992). Por isso, a necessidade de conhecimentos mais aprofundados a respeitodainteraçãodo M. bovigenitaliumeocultivode células do cumulus tornaram-seindispensáveis. Atualmente, diversos sistemas de co-cultivo, conhecidos como "cama de maturação", têm sido utilizados no desenvolvimento de embriões.

A infecção de culturas celulares com Mycoplasmas pode ter diferentes efeitos citogenéticos. Estas bactérias podem aderir a células epiteliais, competir por nutrientes, interagir com células principalmente pelas proteínas da membrana, e liberar compostos de metabolismo primário e/ou secundário. Podem fundir com a membrana citoplasmática, produzir trocas antigênicas ou mesmo invadir a célula hospedeira, interferindo na sua fisiologia e mimetizando uma resposta imune (TIMENETSKY et al., 2006; RAZIN et al., 1998; SyLla et al., 2005).

Uma contaminação por Mycoplasma pode ser imperceptível às manipulações da FIV, pois células infectadas por esse grupo de bactérias não apresentam turvações no meio de cultura, nem mesmo alteração de $\mathrm{pH}$, o que não demonstra contaminação na referida cultura, e quando não lisam a célula hospedeira, tornam mais suscetível ao ambiente e a outros agentes infecciosos, tendo assim uma ação tardia, proporcionando uma maior disseminação do patógeno. Os metabólitos e componentes da membrana dos micoplasmas são biologicamente ativos e, portanto, interferem na interpretação de ensaios laboratoriais.

Odescolamento das células do cumulus cultivadas in vitro, contaminadas com o agente, iniciou-se após $\mathrm{o} 7^{\mathrm{o}} \mathrm{dia}$, enquanto que a cultura controle, descolou-se da placa apenas a partir do $13^{\circ}$ dia. Teoricamente, por se tratar de um agente presente no trato reprodutivo posterior de bovinos, os complexos cumulus-oophorus podem estar contaminados durante o processo de produção in vitro de embriões (PIV), porém não serão diagnosticados anteriormente à transferência do embrião, o que é observado entre o sétimo e oitavo dia após a FIV. Porém, durante a referida fase, as células do cumulus já estariam descartadas, o que dificultaria o diagnóstico para $M$. bovigenitalium e, consequentemente, o embrião seria transferido já contaminado.

Estudos realizados com culturas primárias de oviduto bovino (BOEC) também apresentaram efeitos tardios ligados à alterações morfológicas quando expostos ao patógeno.

Desde que a introdução de antibióticos nos meios de cultivos de células minimizou o problema das contaminações bacterianas e fúngicas, os micoplas- mas passaram a ser os contaminantes detectados com maior frequência em células animais cultivadas in vitro.

Segundo Stringfellow et al. (1998), apesar do tratamento com antibióticos como penicilina, estreptomicina e anfotericina $\mathrm{B}$, realizadas após a exposição in vitro ao patógeno, todos os embriões apresentaram-se contaminados com o M. bovigenitalium, demonstrando que o tratamento não apresenta eficiência.

Por não existir conhecimento relevante sobre a frequência deinfecções causadas pelo $M$. bovigenitalium no processo dePIV, estudos mais aprofundados sobre a qualidade em PIV, coleta de ovários provenientes de abatedouros, acompanhamento veterinário de doadoras, antes de serem abatidas, ou mesmo oócitos puncionados através de ultrasom, devem ser realizados, a fim de que não sejam contaminados pelo patógeno.

\section{REFERÊNCIAS}

AHMED, A.; SABRY, M.; ZAKI, K.M. Possible role of Mycoplasmas in some reproductive disordes of cattle and buffaloes in Egypt. Egyptian Journal of Veterinary Science, v.32, p.115-122, 1998.

BRITTON, A.P.; MILLER, R.B.; RUNKE, H.L.; JOHNSON, W.H. The recovery of Ureaplasmas from bovine embryos following in vitro exposure and ten washes. Theriogenology, v.30, p.997-1003, 1998.

D'ANGELO, M. Interação do herpesvírus bovino tipo 1 (BHV-1) com oócitos bovinos maturados in vitro. 1998. 52p. Tese (Doutorado em Ciências) - Departamento de Microbiologia do Instituto de Ciências Biomédicas, Universidade de São Paulo, 1998.

D'ANGELO, M.; GALUPPO, A.G.; GONÇALVES, R.F. Estudo comparativo da sensibilidade de culturas primárias de células epiteliais de oviduto bovino e murino ao BHV-1. Arquivos do Instituto Biológico, São Paulo, v.69, n.4, p.19-22, 2002.

D'ANGELO, M.; SILVA, S.A.C.M.; SENEDEZI, M.L.P.; GONÇALVES, R.F.; GALUPPO, A.G.; BARRA, S.H.C.; MELO, G.M.; ZERIO, N.M.C. Morphological evaluation of mice zygotes experimentally infected by Brucella abortus. Biology of Reproduction, v.68, p.163, 2003d. Supplement 1. Trabalho apresentado na ANNUAL MEETING OF THE SOCIETY FOR THE STUDY OF REPRODUCTION, 36., 2003, Cincinnati. Resumo 124.

DOIG, P.A. Bovine genital mycoplasmosis. Canadian Veterinary Journal, v.22, p.339-343, 1981.

EAGLESOME, M.D.; GARCIA, M.M.; STEWART, R.B. Microbial agents associated with bovine genital tract infections and semen. Part II. Haemophilus somnus, 
Mycoplasma spp. and Ureaplasma spp., Chlamydia; Pathogens and semen contaminats; treatment of bull semen with antimicrobial agents. Veterinary Bulletin, v.62, p.887-910, 1992.

GONÇALVES, R.F.; D’ANGELO, M.; GALUPPO, A.G. Uso da microscopia eletrônica de varredura na avaliação morfológica de células epiteliais de oviduto bovino in vitro. Arquivos do Instituto Biológico, v.64, p.150, 1977. Suplemento. Trabalho apresentado na REUNIÃO ANUAL DO INSTITUTO BIOLÓGICO, 10., 1997. São Paulo. Resumo 60.

HERNANDEZ-LEDEZMA, J.J.; VILLANUEVA, C.; SIKES, J.D.; ROBERTS, R.M. Effects of CZB versus médium 199 and of conditioning culture media with bovine oviductal epithelial cells or buffalo rat liver cells on the development of bovine zygotes derived by in vitro fertilization procedures. Theriogenology, v.39, p.1267-1277, 1993.

KIRKBRIDE, C.A. Mycoplasma, ureaplasma, and acholeplasma infections of bovine genitalia. Veterinary Clinics of North America: Food Animal Practice, v.3, p.575591, 1987.

KRISHER, R.L.; BAVISTER, B.D. Responses of oocytes and embryos to the culture environment. Theriogenology, v.49, p.103-114, 1998.

MILLER, R.B.; CHELMONSKA-SOYTA, A.; SMITS, B.; FOSTER, R.; ROSENDAL, S. Ureaplasma diversum as a cause of reproductive disease in cattle. Veterinary Clinics of North America: Food Animal Practice, v.10, p.479-490, 1994.

MINAMI, N. Early embryonic development under oviductal influence in vitro. Animal Reproduction Science, v.42, p.361-369, 1996.

NASCIMENTO, M.G.F.; D'ANGELIS, F.H.F.; NASCIMENTO, E.R.; RESENDE, A.O. Envolvimento de micoplasmas em vacas com distúrbios reprodutivos. Acta Scientiae Veterinariae, v.33, n.2, p.195-199, 2005.
RAZIN, S.; YOGEV, D.; NAOT, Y. Molecular Biology and Pathogenicity of Mycoplasmas. Microbiology and Molecular Biology Reviews, v.62, n.4, p.1094-1156, 1998.

SPARKS, A.E.T.; GWAZDAUSK, F.C.; McGILLIARD, M.L. Nonspecies-specific effects of mouse oviducts on the development of bovine IVM/IVF embryos by a serum free co-culture. Theriogenology, v.41, p.1435-1445, 1994.

SPARKS, A.E.T.; GWAZDAUSKAS, F.C.; McGILLIARD, M.L. Culture of one-cell bovine embryos in explanted mouse oviduct an bovine oviductal epithelial cells. Theriogenology, v.36, p.585-594, 1992.

STRINGFELLOW, D.A.; SEIDEL, S.M. Manual da Sociedade Internacional de Transferência de Embriões: guia de procedimentos e informação geral para uso da tecnologia de transferência de embriões, enfatizando precauções sanitárias. 3.ed. Illinois: IETS, 1998. p.95.

STRINGFELLOW, D.A.; GIVENS, M.D.; WALDROP, J.G. Biosecurity issues associated with current and emerging embryo technologies. Reproduction, Fertility and Development, v.16 p.93-102, 2004.

SYLLA, L.; STRADAIOLI, G.; MANUALI, E.; ROTA, A.; ZELLI, R.; VINCENTI, L.; MONACI, M. The effect of Mycoplasma mycoides ssp. mycoides LC of bovine origin on in vitro fertilizing ability of bull spermatozoa and embryo development. Animal Reproduction Science, v.85, p.81-93, 2005.

THIBIER, M.; GUERIN, B. Hygienic aspects of storage and use of semen for artificial insemination. Animal Reproduction Science, v.62, p.233-251, 2000.

TIMENETSKY, J.; SANTOS, L.M.; BUZINHAMI, M.; METTIFOGO, E. Detection of multiple mycoplasma infection in cell cultures by PCR. Brazilian Journal of Medical and Biological Research, v.39, n.7, p.907-914, 2006.

Recebido em $27 / 6 / 11$

Aceito em 15/10/12 